\title{
O imperativo categórico kantiano em face da falibilidade moral da terceirização do trabalho no direito brasileiro
}

\section{The Kantian cathegorical imperative in the face of moral fallibility of labor outsourcering in the Brazilian law}

\author{
VICTOR AUGUSTO KONDRAT DA SILVA ${ }^{1}$ \\ KATIA SALOMÃO ${ }^{2}$ \\ ANTONELLA MARQUES NEVES ${ }^{3}$
}

\begin{abstract}
Resumo: O presente trabalho possui o objetivo de mostrar como a Terceirização do Trabalho, enquanto um fenômeno moderno do Direito do Trabalho no Brasil, especialmente após a Lei 13.467/2017 ter alterado a Consolidação das Leis do Trabalho, seria imoral e ilegítimo por negligenciar diretamente o imperativo categórico e a pessoa humana em sua Dignidade, sob a luz da teoria de Kant acerca da Moralidade.

Palavras-Chave: Kant. Moral. Terceirização do Trabalho. Lei. 13.467/2017.
\end{abstract}

Abstract: The present work aims to show how Labor Outsourcing, as a modern phenomenon of Labor Law in Brazil, especially after Law 13.467/2017 changed the Consolidation of Labor Laws, it would be immoral and illegitimate because it directly neglects the categorical imperative and the human person in their Dignity, in the light of Kant's theory about Morality.

Keywords: Kant. Moral. Labor Outsourcing. Law. 13,467/2017.

\section{Introdução}

O presente artigo tem o objetivo de estudar o fenômeno da Terceirização do Trabalho na Lei 13.467/2017, sob o enfoque do Princípio Supremo da Moralidade de Kant, analisando - a partir de sua teoria - a moralidade desse fenômeno.

Este tema surge da necessidade de trazer à tona a discussão sobre a moralidade acerca da Terceirização do Trabalho, tendo em vista que, muitas vezes, não respeita a Dignidade da Pessoa Humana - e, por consequência, como será observado ao longo do artigo, não respeita as premissas do Imperativo Categórico de Kant, ocasionando uma condição imoral, em face de tal escopo teórico.

Sendo assim, a problemática que norteou este Artigo foi: é correto afirmar que a Terceirização do Trabalho, como fenômeno do Direito do Trabalho, é Imoral à luz da Teoria Kantiana do Princípio Supremo da Moralidade? Sendo assim, com os esforços voltados para responder tal questionamento, o presente artigo analisou a Terceirização do Trabalho à luz da teoria de Kant acerca do Princípio Supremo da Moralidade, buscando nas contradições que sobressaem de tal análise o fomento de

${ }^{1}$ Centro Universitário de Cascavel - UNIVEL. E-mail: kondratvictor@gmail.com

22Doutoranda em Filosofia pela Unioeste. E-mail: salomao@univel.br

${ }^{3}$ Mestranda em educação pela Unioeste - Cascavel. E-mail: antonellaneves@yahoo.com.br 
uma reflexão crítica e dialética acerca do tema.

Portanto, desconfia-se no que tange a tal abordagem - em detrimento da bibliografia utilizada e analisada - que o fenômeno da Terceirização do Trabalho, na Lei 13.467/17 - frente às teorias kantianas -, é imoral. Para comprovar tais suspeitas, primeiro, foi analisado o processo de retrocesso presente na Lei 13.467/2017, na qual consta a terceirização do trabalho e seu processo de legalidade.

\subsection{Terceirização do trabalho na Lei 13.467/2017}

No dia 13 de julho de 2017, foi publicada, oficialmente, a Lei 13.467 (cuja vigência ocorreu a partir do dia 14/o7/2017), que alterou a Consolidação das Leis do Trabalho (Decreto-lei ${ }^{\circ}{ }^{\circ} \cdot 452 / 1943$ ), juntamente com as Leis 6.019/1974 (Trabalho Temporário), 8.036/1990 (FGTS) e 8.212/1991 (Seguridade Social).

Dentre todos os institutos alterados pela nova Lei, um deles foi a Terceirização do Trabalho (foco dessa pesquisa), que é: “(...) um fenômeno pelo qual se dissocia a relação econômica de trabalho da relação justrabalhista que lhe seria correspondente" (DELGADO, 2016, p. 487). Além disso, a Lei prevê que a Terceirização é "a transferência feita pela contratante da execução de quaisquer de suas atividades, inclusive sua atividade principal, à pessoa jurídica de direito privado prestadora de serviços que possua capacidade econômica compatível com a sua execução" (Artigo 4- da Lei 6.019/1974, com redação dada pela Lei 13.467/2017). Sendo assim, o Trabalhador contratado realizará serviços para a empresa contratante, mas quem responderá pelos seus direitos empregatícios é empresa prestadora de serviços.

Além de verificar o Artigo $4^{\circ}$ da Lei 6.019/1974 (alterada pela Lei 13.467/2017), pode-se analisar, ainda, o $\$ 2^{\circ}$ do Artigo $4^{\circ}$ da Lei citada, o qual dispõe: "não se configura vínculo empregatício entre os trabalhadores, ou sócios das empresas prestadoras de serviços, qualquer que seja o seu ramo, e a empresa contratante" ${ }^{4}$. Ademais, nessa senda, como explica Filho:

Dessa forma, a típica relação bilateral entre empregado e empregador se rompe e cria-se uma relação trilateral onde o obreiro realiza atividades - materiais e intelectuais - para a empresa tomadora de serviço, a empresa terceirizante (empregadora aparente) que contrata o empregado, criando vínculos trabalhistas com ele, e a empresa tomadora de serviços (empregadora real) recebe a prestação laboral sem assumir a posição típica de empregadora do trabalhador em questão. Ainda, na Terceirização, há uma relação contratual entre a empresa tomadora e a terceirizante em que esta fornece o serviço (que será prestado pelo obreiro) àquela, a qual irá realizar o pagamento à fornecedora do serviço, sem que o trabalhador seja pago diretamente pela

4 Artigo $4^{\circ}$-A, $\S 2^{\circ}$ da Lei 6.019/1974, com redação dada pela Lei 13.467/2017. 
tomadora. (2018, p. 34).

Por isso, pode-se afirmar que esse novo modelo de contratação surge no contexto neoliberal, no qual o avanço do capitalismo mostrou a necessidade de descentralizar as atividades da empresa, a fim de que as atividades secundárias pudessem ser realizadas por outras. Com essa estratégia, a empresa contratante lucraria por não ter a necessidade de investir nas atividades secundárias e a empresa prestadora de serviço seria beneficiada por prestar tal serviço. Desse modo, por mais que isso beneficie as empresas, "a terceirização acaba por se mostrar como uma forma de precarização de direitos trabalhistas, em que, mais uma vez, se prejudica o trabalhador para elevar o lucro da empresa" (FILHO, 2018, p. 35).

Para Filho (2018), o indivíduo terceirizado, que foi designado a executar o serviço, encontra-se em uma situação de degradação das condições de trabalho, uma vez que sua jornada é mais prolongada e sua remuneração é reduzida, o que transforma o trabalhador em uma ferramenta (ou mercadoria), isto é, transforma a pessoa em meio para fim, coisificando-a. E, sendo a pessoa digna em si mesma, ela tem sua essência de pessoa ferida e negligenciada pela lei, em que sua dignidade humana foi afetada pelo processo normativo que pode até ser considerado legal, mas não pode ser legitimamente moral, de acordo com os pressupostos do imperativo categórico (e da dignidade humana) em Kant.

Portanto, além de fazer com que o trabalhador labute por jornadas mais longas e com que ele receba menos por isso, a terceirização tem efeitos na esfera moral, vez que esse fenômeno trata o trabalhador como um mero objeto, coisificando o ser humano "de modo que ele se assemelhe em muito com um contrato de arrendamento, em que uma das partes aluga os trabalhadores para a outra, da mesma forma que se aluga uma máquina" (FILHO, 2018, p. 38).

Vale ressaltar que o Brasil é membro da Organização Internacional do Trabalho (OIT) desde 1950. Essa Organização, no Brasil e no mundo, tem como objetivo a promoção permanente da melhoria das condições de trabalho e da ampliação da proteção social, buscando promover um trabalho digno (decente) aos indivíduos.

Para a OIT (2018), o trabalho digno abrange diversos elementos, como: garantia de oportunidades capazes de promover um trabalho produtivo, com remuneração equitativa; segurança no ambiente de trabalho; proteção social para as famílias; a ampliação das perspectivas de desenvolvimento pessoal e integração social; assegurar a liberdade para que o trabalhador possa se expressar com relação a suas preocupações; maior participação nas decisões que o afetam e a liberdade de gênero com relação a oportunidades de tratamento.

Dessa forma, pode-se concluir que o trabalho digno é aquele que, além de preservar a integridade física do trabalhador, possibilitando condições adequadas de 
saúde e segurança no ambiente laboral - para garantir meios adequados para sua subsistência, com remuneração compatível e jornada não degradante -, também promove seu engrandecimento, tornando-o consciente de seu papel e sendo capaz de questionar e participar das decisões que o afetem. Esse trabalho decente, portanto, é aquele que assegura ao trabalhador a característica de sujeito, transmitindo a noção de ser um fim e não um meio. Assim, o indivíduo somente consegue trabalhar com dignidade quando não for tratado como um objeto ou ferramenta, mas como um ser humano possuidor de dignidade.

Entretanto, como noticiou o site Conjur (2018), com a Terceirização do Trabalho, muitos desses pontos são violados e a própria OIT, no dia 29/05/2018, colocou o Brasil como sendo um dos países que violam suas convenções trabalhistas no mundo, conforme se verifica em trecho da notícia: "Em nota, as entidades afirmam que esperam que o governo reconheça a gravidade do erro cometido e faça a revogação imediata da reforma trabalhista"

Portanto, nota-se, com inflamada suspeita, que a Reforma Trabalhista, trazida pela Lei 13.467/2017, é um símbolo de retrocesso aos direitos trabalhistas, que outrora foram conquistados, bem como representa uma violação da dignidade da pessoa humana e do Princípio Supremo da Moralidade Kantiano, como será analisado em sequência.

\subsection{Teoria Moral Kantiana}

O ponto de partida do filósofo Immanuel Kant, ao explicar sua teoria acerca da Moralidade, é a constatação de um sujeito racional, capaz de agir de acordo com princípios que determinam suas ações. Para Kant (1999), é apenas esse indivíduo, dotado de racionalidade, que tem a capacidade de agir segundo leis que impõem a si mesmo, afirmando, desse modo, sua capacidade racional.

De acordo com Michael Sandel (2015), o filósofo alemão concebe a ideia de que a lei, imposta pelo indivíduo a si mesmo, precisa estar fundamentada em um Dever Categórico. Tal aspecto não permite que se usem as pessoas como meios para determinados fins, uma vez que todas possuem Dignidade e exigem respeito, por serem seres racionais e capazes de agir autonomamente, conforme explica Kant na Fundamentação da Metafísica dos Costumes (2000, p. 69): "Age de tal maneira que uses a humanidade, tanto na sua pessoa como na pessoa de qualquer outro, sempre e simultaneamente como fim e nunca simplesmente como meio".

Entretanto, Alysson Mascaro (2016) aponta a distinção de Dever e Moralidade que Kant faz em seu livro Crítica da Razão Prática, como forma de ilustrar que seguir um Dever não significa, necessariamente, cumprir a Moralidade. Agir de

\footnotetext{
${ }^{5}$ CONJUR. OIT classifica reforma trabalhista brasileira como violadora de direitos. Disponível em: $<$ https://www.conjur.com.br/2018-mai-29/brasil-entra-lista-suja-oit-causa-reforma-trabalhista> Acesso em: 21 de agosto de 2018.
} 
acordo com o dever é seguir os trâmites da legalidade, mas não significa que isso é, obrigatoriamente, moral.

A moralidade, segundo Kant, não é apenas o cumprimento do dever, mas sim, é o cumprimento do dever sem nenhum outro fundamento que não seja cumprir o próprio dever. Ou seja, "a moralidade se instaura no campo de uma vontade que busca cumprir o dever sem interesses externos" (MASCARO, 2016, p. 217).

Sendo assim, o fundamento que determina a moralidade da ação será a boa vontade, que "não é boa por aquilo que promove ou realiza, pela aptidão para alcançar qualquer finalidade proposta, mas tão somente pelo querer, isto é, em si mesma" (KANT, 2000, p.23).

Além disso, vale ressaltar que o núcleo da moralidade Kantiana baseia-se no conceito do Imperativo Categórico, traduzido na orientação para agir de acordo com a Moralidade racional. Essa moralidade apresenta-se como um imperativo porque "a representação de um princípio objetivo, enquanto obrigante para uma vontade chama-se um mandamento da razão, e a fórmula do mandamento chama-se imperativo" (KANT, 200o, p.124). Ou seja, o imperativo não é apenas um orientador da moral, mas sim, uma obrigação das ações para os entes dotados de racionalidade.

Portanto, somente as ações que seguirem o imperativo categórico poderão ser consideradas como justas e boas. Esse imperativo traduz-se na Lei fundamental da razão pura prática, que é: "Age de tal modo que a máxima da tua vontade possa valer sempre ao mesmo tempo como princípio de uma lei universal" ${ }^{6}$.

Além disso, segundo Mascaro (2016), Kant ainda trata de seus desdobramentos (formulações), que são:

Age como se a máxima da tua ação devesse tornar, pela tua vontade, em lei universal da razão. Age de tal maneira que uses a humanidade, tanto na sua pessoa como na pessoa de qualquer outro, sempre e simultaneamente como fim e nunca simplesmente como meio (KANT, 2000, p. 59-69).

Entretanto, é importante elucidar que as formulações do imperativo categórico não fazem dele múltiplo, uma vez que ele deve ser entendido como uma máxima.

Na mesma senda - acerca da Segunda Formulação - explica Laurence BonJour e Ann Baker:

Todo ente racional existe como um fim em si mesmo e não meramente como um meio para ser usado arbitrariamente por essa ou por aquela vontade. Em todas as suas ações, não importa se elas são direcionadas a si mesmo ou a outros entes racionais, ele sempredeve ser considerado ao mesmo tempo como um fim.

\footnotetext{
${ }^{6}$ KANT, Immanuel. Crítica da Razão Prática. Lisboa: Edições 70, 1999, p. 183.
} 
(BONJOUR; BAKER, 2010, p. 437).

Sendo assim, ao utilizar uma pessoa como meio - violando a sua dignidade e utilizando-a como mero meio - Ann Baker e Laurence BonJour (2010) afirmam que aquele que faz as outras pessoas como meio, sem considerá-las como entes racionais estimadas como fins, transgride os direitos dos homens e de sua dignidade.

Segundo Laurence BonJour e Ann Baker (2010, p. 448): "Kant diria que embora eles se usem uns aos outros como meios, eles não se usam como meros meios" (grifo nosso). Ou seja, a pessoa que é enganada, coagida, ludibriada, forçada, instrumentalizada - por assim dizer - é utilizada como mero meio, uma vez que há uma relação de objetificação para com essa pessoa. Por fim, os autores explicam:

Na perspectiva de Kant, atos que são praticados a partir de máximas que requerem engano ou coerção dos outros - e, portanto, não podem ter o seu consentimento (pois o consentimento previne tanto o engano quanto a coerção) - são errados. Quando agimos sob tais máximas, tratamos os outros como meros meios, como coisas em vez de fins em si mesmos. Se agimos sob tais máximas, nossos atos não são apenas errados, mas também injustos: tais atos usam os outros que são enganados e coagidos. (BONJOUR; BAKER, (2010), p. 449).

Na mesma senda, é oportuno citar Weber (2013, p. 27), que afirma que: “o grande contraponto da dignidade é a humilhação. $\mathrm{O}$ homem não é uma coisa que eu possa simplesmente utilizar como meio, mas é fim em si mesmo. [...] Violar os direitos humanos significa servir-se dos outros simplesmente como meios e não como fins".

Além disso, vale ilustrar o que Ingo Wolfgang Sarlet (2015) explica sobre o assunto:

Kant sustenta que "o Homem, e, duma maneira geral, todo o ser racional, existe como um fim em si mesmo, não simplesmente como meio para o uso arbitrário desta ou daquela vontade. Pelo contrário em todas as suas ações [...] ele tem sempre de ser considerado simultaneamente como um fim [...] quer dizer, como algo que não pode ser empregado como simples meio e que, por conseguinte [...] é um objeto de respeito." (KANT apud SARLET, 2015, p. 40).

Dessa forma, quando uma coisa é considerada como um fim - e quando essa pessoa está infinitamente acima de todo o preço, nunca podendo essa pessoa ser posta em cálculo ou em confronto com algo que haja preço - então, ela tem sua dignidade respeitada. Ou seja, tratar alguém como um fim requer, primeiramente, que não se utilize dessa pessoa como um mero meio - passível de ter um preço - e que se respeite cada pessoa racional como possuidora de dignidade e possuidora de suas máximas. 
Portanto, ao focar na sua Segunda Formulação do imperativo categórico, podese chegar à conclusão de que muitas das relações sociais - principalmente as relações trabalhistas, especificadamente no que tange ao fenômeno da Terceirização do Trabalho - negligenciam essa máxima, tornando-se imorais e ilegítimas sob a luz da teoria Kantiana. Não obstante, a pessoa humana está submetida à lei pelos contratantes e pelo Estado de Direito; por um lado, ela resguarda acesso aos benefícios e salários, mas, por outro, é cruelmente instaurada e coage a dignidade de cada ente ao seu esvaziamento simbólico, inerente à formalidade jurídica.

\subsection{Imoralidade na terceirização do trabalho sob o enfoque do Imperativo Categórico Kantiano}

Como explica Michael Sandel (2015), Kant coloca como "Princípio Supremo da Moralidade" dois desdobramentos do imperativo categórico, cuja finalidade seria nortear (imperativamente) como se deveria agir para que a ação tomada fosse moral. Considerando a Segunda Formulação do imperativo categórico, vê-se que, para uma ação ser moral, os indivíduos deveriam tratar-se como fins em si mesmos, jamais objetificando uns aos outros (tornando-os ferramentas).

Sendo assim, ao observar o fenômeno da Terceirização do Trabalho, deduz-se que essa prática é, sob a ótica Kantiana, fundamentalmente imoral, tendo em vista que "a terceirização é a coisificação do ser humano [...] assim, o indivíduo que antes era tratado como sujeito de direitos perde tal status e se torna um objeto com direitos." (FILHO, 2018, p. 39). Ainda nessa senda, como explica Artur Filho (2018):

O Direito do Trabalho vem se flexibilizando a ponto de admitir a conversão do sujeito em objeto. [...] Assim, a essência do ramo trabalhista do Direito vai se perdendo ao admitir que o trabalhador atinja a condição de mero objetoa ser alugado. (FILHO, 2018, p. 39).

Portanto, o fenômeno da Terceirização do Trabalho, à luz da teoria Kantiana acerca da moralidade, denota um indivíduo sujeito à terceirização, que está reduzido à condição de objeto (por meio da coisificação) e, assim, é tratado como tal, sendo sempre um meio para os fins de quem os emprega.

Entretanto, surge um problema lógico, que deriva da Segunda Formulação do imperativo categórico, que é: independentemente do que se faça, cotidianamente, utilizam-se as pessoas como meios para fins; por exemplo, o aluno que utiliza o professor como meio para obter o fim 'conhecimento'. Sendo assim, chega-se à conclusão de que é impossível realizar as práticas cotidianas sem, ao menos uma vez, utilizar-se de outras pessoas como meio.

Vale ressaltar que, segundo Michael Sandel (2009), segundo a própria teoria Kantiana, realizar tais condutas não viola o imperativo categórico, conforme ele explica: 
Não viola o imperativo categórico quando você utiliza outras pessoas como meio. Isso não é censurável, contanto que, ao lidarmos com o outro para levar adiante projetos e interesses, coisa que todo mundo faz, tratemos o outro de forma a respeitar sua dignidade, e o significado de respeitá-lo é proporcionado pelo imperativo categórico. (SANDEL, 2009, 53m16s) ${ }^{7}$.

Sendo assim, deve-se analisar qual a situação (concreta) para compreender se há ou não há o respeito do imperativo categórico Kantiano. Nesse sentido, frente à teoria Kantiana, a Terceirização na Reforma Trabalhista viola a dignidade dos trabalhadores terceirizados, uma vez que são utilizados, muitas vezes, como objetos (ferramentas), meros meios para um determinado fim.

Nessa senda, sob o enfoque Kantiano, a Terceirização no Direito do Trabalho seria vista como Imoral, tendo em vista que esse fenômeno viola as formulações do imperativo categórico, bem como desrespeita a dignidade da pessoa humana do trabalhador, que está sujeito a esse trabalho. Além disso, a grande questão é que a Terceirização, em si, já seria por si só Imoral, mas, com a Reforma Trabalhista de 2017, além de flexibilizar a Terceirização (ou seja, facilitar para que esse fenômeno continue ocorrendo e com menos direitos aos trabalhadores), ela prejudicou muito os direitos que outrora já haviam sido adquiridos por essa classe.

Portanto, a Reforma Trabalhista mostra-se contrária à moral Kantiana, bem como evidencia-se contrária à dignidade de pessoa humana, tendo em vista que ela coisifica o trabalhador, reduzindo-o a meios (meras ferramentas) para outros fins (lucro das empresas).

\section{Conclusão}

Conforme foi analisado ao longo dessa pesquisa, o fenômeno da Terceirização do Trabalho, flexibilizado na Reforma Trabalhista de 2017, mostra-se como retrocesso no Direito do Trabalho, bem como uma violação à dignidade da pessoa humana e ao Princípio Supremo da Moralidade Kantiana, fundamentada nas formulações do imperativo categórico. Nota-se, principalmente, que há a violação da Segunda Formulação do Imperativo Categórico, a qual dispõe que não se deve instrumentalizar ninguém (e é justamente isso que, segundo Filho (2018), a Terceirização - ainda mais após a Reforma - faz).

Portanto, conclui-se que, sob o enfoque do pensamento Kantiano acerca do Princípio Supremo da Moralidade (estabelecido por meio das formulações do imperativo categórico), a Terceirização do Trabalho como fenômeno do Direito do Trabalho, flexibilizado pela Lei 13.467/2017 (Reforma Trabalhista), é Imoral, tendo

\footnotetext{
${ }^{7}$ SANDEL, Michael. Justice: What's The Right Thing To Do? Episode o6: "MIND YOUR MOTIVE". YouTube. Harvard University. 8 set. 2009. Duração: (55m13s). Disponível em: <https://www.youtube.com/watch?v=8rv-4aUbZxQ>. Acesso em: 14 ago. 2018.
} 
em vista que viola os preceitos do imperativo categórico e desrespeita a dignidade da pessoa humana por instrumentalizar (coisificar) o trabalhador terceirizado.

\section{Referências}

BONJOUR, Laurence; BAKER, Ann. Filosofia: textos fundamentais comentados. $2^{a}$ Edição. Porto Alegre: Artmed, 2010.

DELGADO, Maurício Godinho. Curso de Direito do Trabalho. 15ª Edição. São Paulo: LTr, 2016.

FILHO, Artur Adolfo Cotias e Silva. Monografia. bdm.unb.br. 2017. Disponível em: <http://bdm.unb.br/bitstream/10483/17596/1/2017_ArturAdolfoCotiaseSilvaFilho.pdf>. Acesso em: 14 ago. 2018.

GARCIA, Gustavo Filipe Barbosa. Curso de Direito do Trabalho. 11. ed. Rio de Janeiro: Forense, 2017.

KANT, Immanuel. Crítica da Razão Prática. Lisboa: Edições 70, 1999.

KANT, Immanuel. Fundamentação da Metafísica dos Costumes. São Paulo: Abril cultural, 200o. (Coleção os Pensadores).

MASCARO, Alysson Leandro. Filosofia do Direito. 5 ed. Ver., atual. e ampl. - São Paulo: Atlas, 2016.

Organização Internacional do Trabalho (OIT). Trabalho digno - a chave do progresso social. 15 de dez. 2010. Disponível em: <http://www.ilo.org/public/portugue/

region/eurpro/lisbon/html/portugal.> Acesso em: 14 ago. 2018;

SANDEL, Michael. Justice: What's The Right Thing To Do? Episode o6: "MIND YOUR MOTIVE". YouTube. Harvard University. 8 set. 2009. Duração: (55mı3s). Disponível em: <https://www.youtube.com/watch?v=8rv-4aUbZxQ.> Acesso em: 14 ago. 2018.

SANDEL, Michael. Justiça [recurso eletrônico] / Michael J. Sandel; tradução de Heloisa Matias e Maria Alice Máximo. - Rio de Janeiro: Civilização Brasileira, 2015.

SARLET. Ingo Wolfgang. Dignidade (da pessoa) humana e direitos fundamentais na Constituição Federal de 1988. 10a Edição. Porto Alegre: Livraria do Advogado Editora, 2015.

WEBER, Thadeu. Ética e Filosofia do Direito: autonomia e dignidade da pessoa humana. Petrópolis, Rio de Janeiro: Vozes, 2013.

Submissão: 10.10.2018 / Aceite: 20.12.2019 